\title{
Proceedings of The Society of Thoracic and Cardiovascular Surgeons of Great Britain and Ireland
}

The Annual Meeting of The Society of Thoracic and Cardiovascular Surgeons of Great Britain and Ireland was held on 28 and 29 September 1978 at the University of Leeds. Summaries of the papers follow:

\section{Killingbeck lusterlite valve}

D A WATSON, A J MEARNS, and F DEXTER Sixty patients had mitral valve replacement with an irradiated mounted homograft aortic valve. There were two operative deaths and 12 late deaths. Anticoagulants were not used. Three patients had infective endocarditis. There were three sudden deaths unrelated to the valve. Of the late deaths, five were at reoperation for valve failure. At one year, the 50 patients who survived were in grade I (NYHA). Haemodynamic studies on nine patients showed very adequate valve function with statistically significant changes in pulmonary wedge pressure $(P=0 \cdot 01)$, pulmonary arterial pressure $(P=0.01)$, and cardiac output at rest $(P=0.05)$. Haemolytic studies showed no haemolysis. All 50 patients, who were well at one year, showed statistically significant improvements in cardiothoracic diameter and QRS axis. There were no late embolic incidents, although one patient, who had a clot in the left atrium at operation, died within three months of cerebral embolus incurred at the time of operation.

At present 27 patients are still alive with the original homograft valve, and 16 patients are alive after removal of the valve for valve failure. Follow-up is complete from four to eight and a half years on all patients. All the figures are actuarially presented.

We conclude that the Killingbeck lusterlite valve is a good valve that functions well with the patients back to grade I with good haemodynamic findings at one year. Unfortunately, the longevity of the valve is suspect and there is a $25 \%$ structural valve failure rate at five years. Histology of the removed valves shows that there is very little invasion by host cells. Evidence of stress deterioration of the cusps is present in all specimens removed for valve failure, but the histology is not different in valves removed at death from unrelated causes when the valve was functioning normally.

\section{Long-term clinical and haemodynamic evaluation of the Ionescu-Shiley pericardial xenograft heart valve}

M I IONESCU, A $P$ TANDON, A J MEARNS, and $M$ F ROESLER Glutaraldehyde stabilised pericardial xenografts (PX) were used in 411 patients from 1971. Three hundred and sixty-nine patients had single valve replacement (216 aortic, 150 mitral, three tricuspid), and 42 had multiple replacements. The 385 hospital survivors have been followed up for three to 90 months (total 11895 ). Actuarial survival rate ( $\pm \mathrm{SE}$ ) at eight years is $83.5( \pm 10.5) \%$ for patients with aortic and $88.9( \pm 6.9) \%$ for patients with mitral replacement. Long-term anticoagulation was not used. $98.3( \pm 0.9) \%$ of patients with aortic and $96.4( \pm 1.8) \% \omega$ of patients with mitral replacement are expected to be free from emboli at one and eight years after opera- $\vec{\omega}$ tion. The embolic rate was 0.49 and 1.22 episodes per 100 patient years respectively. All emboli (three in the 음 aortic and four in the mitral groups) occurred in the first six weeks and were mild and transient. There was $T$ no valve thrombosis in this entire series. Symptomatic- $\frac{D}{O}$ ally $93 \%$ of patients are now in class I (NYHA). Laboratory studies failed to show evidence of chronic intravascular haemolysis in either mitral or aortic patients. Microscopy showed maintenance of structural integrity of all PX examined.

Haemodynamic studies were performed in 36 patients with aortic (AR) and in 29 patients with mitral valve replacement (MR) at mean intervals of $41 \cdot 2$ (range 22-59) and 40.2 (range 24-59) months $\overline{0}$ after operation respectively. Significant haemodynamic 응 improvement was noted in both groups. In the AR $\Omega$ group the mean peak systolic gradient was $6 \mathrm{mmHg}$ at $\overrightarrow{\vec{A}}$ rest and $9.5 \mathrm{mmHg}$ on exercise. The highest gradients recorded with the smallest valves $(19 \mathrm{~mm})$ were $8: 3 \frac{\mathrm{J}}{\mathrm{J}}$ $\mathrm{mmHg}$ at rest and $12.3 \mathrm{mmHg}$ on exercise. Calculated xenograft surface area varied from $1 \cdot 1$ to $2 \cdot 1 \mathrm{~cm}^{2}$ at rest and 1.3 to $2.4 \mathrm{~cm}^{2}$ on exercise. In the MR group the mean diastolic gradient was $6 \mathrm{mmHg}$ at rest and $15 \mathrm{mmHg}$ on exercise and the mean xenograft surface ? area $2.0 \mathrm{~cm}^{2}$ at rest and $2 \cdot 3 \mathrm{~cm}^{2}$ on exercise (valve sizes 25,27 , and $29 \mathrm{~mm}$ ). Comparison of data from sequential haemodynamic studies performed in $13 \mathrm{AR} \delta$ and six MR showed no significant changes between the circulatory parameters recorded at a mean of 9.9 응 and 42.2 months after operation. In-vitro fatigue testing proved the durability of the pericardial xenograft $\frac{7}{0}$ to be more than 26.5 years.

Detailed analysis of the results over 7.5 years has $N$ shown a very low embolic rate without anticoagulant treatment, an insignificant number of valve related $\mathcal{O}$ complications, and very good long-term clinical and $N$ haemodynamic performance of the pericardial xenograft, even in small aortic sizes.

Arterial return microfiltration during cardiopulmonary bypass-a randomised study in patients undergoing coronary artery surgery

DUNCAN $R$ WALKER One hundred and two patients undergoing coronary artery surgery were randomised $\unrhd$ into two equal groups. One group had insertion of $\bar{\gamma}$ 
an arterial microfilter (PALL filter). The effects of filtration on various subsystems were studied. Preand postoperative alterations in $\mathrm{A}$-ado, creatinine clearance, indocyanine green dye liver function tests, haematological variables, and psychometric tests were recorded as well as the effect on postoperative blood loss and evolution of heart-specific isoenzymes. No differences were found between the filter and the nonfilter group except that the platelet count was depressed significantly greater $(P<0.05)$ in the filter group and $\mathrm{A}-\mathrm{adO}_{2}$ was $29 \mathrm{mmHg}$ higher at three hours in the non-filter group $(P=0 \cdot 1)$.

Postoperative blood loss and plasma haemoglobin levels were similar. All IQ scales were lower six days postoperatively than preoperatively. The verbal IQ fell $1 \cdot 8 \pm 1 \cdot 27$ (mean \pm SE) in non-filter vs $2 \cdot 0 \pm 1 \cdot 19$ $(P>0.7)$ in the filter group. Performance IQ $1.6 \pm 1.72$ vs $3.9 \pm 1.63(P>0.9)$ and full scale IQ $3.9 \pm 1.29$ vs $3 \cdot 1 \pm 1 \cdot 17(\mathrm{P}>0 \cdot 8)$.

In ten of the 51 patients, a gradient was recorded across the filter greater than $80 \mathrm{mmHg}$, and in five of these patients the gradient rose sufficiently high to discontinue the filtration and bypass the filter.

This study shows that for this important cardiac surgery subgroup an arterial filter is neither dangerous nor of benefit and that if a filter is used in the arterial return a bypass line should be incorporated.

False ventricular aneurysms-unusual case report and brief review of the literature

A $\mathrm{K}$ DEIRANIYA Post-infarction false ventricular aneurysms are rare and result from a slowly progressive cardiac rupture and its containment by pericardial adhesions. In contradistinction to true aneurysms they have a small os to fundus ratio and dense acellular walls, and they are particularly prone to rupture with fatal results. Left ventriculography is diagnostic. Of 28 reported cases, 17 were diagnosed at necropsy and 11 were surgically treated, with two deaths.

The case report describes a surgically treated false left ventricular aneurysm arising from the lateral left ventricular wall, traversing the transverse sinus and re-emerging between the superior vena cava and the aorta to overlie the proximal right atrium and the atrioventricular groove, with a communication between the floor of the aneurysm in the transverse sinus and the roof of the left atrium, which was not suspected before operation. This communication, which must represent a particularly fortunate form of rupture into a cardiac chamber, became apparent during the course of the operation. Such a case has not been previously reported.

The natural history of false ventricular aneurysms is similar to that of true ventricular aneurysms, except that the risk of rupture is very much higher and indicates early surgery.

\section{Rupture of the ascending aorta in association with coarctation of the aorta}

R A M LAWSON and A FENN A previously fit 21-yearold man presented with severe central chest pain.
Clinical, radiological, electrocardiographic, and echocardiographic examination confirmed rupture of the ascending aorta in the presence of previously undiagnosed severe aortic coarctation. The initial rupture had occurred five days before admission. The medical and staged surgical management of the case are presented. Surgical survival with such a combination of lesions does not appear to have been previously reported.

\section{Endomyocardial fibrosis}

$\mathrm{U}$ NAIR and $\mathrm{H}$ H BENTALl Endomyocardial fibrosis (EMF) was first described by Bedford and Koustan in 1946. It is probably an autoimmune disease of unknown aetiology producing fibrosis of the endomyocardium. Lepley et al reported the first successful surgical treatment of such a lesion of the left ventricle. Replacement of the mitral valve was necessary in most of the surgically treated lesions of the left ventricle. We report the surgical treatment of a typical case of EMF of the left ventricle, in which we were able to preserve the mitral valve apparatus. The patient is well and back at work eight months after surgery.

Preoperative low-dosage propranolol: its effect on left ventricular function and its protective value from ischaemia

A HEDLEY-BROWN and B L KRAUSE Isovolumic function tests of hearts "in situ" in dogs on cardiopulmonary bypass show that:

(1) the $20 \mu \mathrm{g} / \mathrm{kg}$ of propranolol suggested for myocardial protection from ischaemia does significantly reduce myocardial contractility but that this recovers within 90 minutes;

(2) ninety minutes of ischaemia with preliminary propranolol $(20 \mu \mathrm{g} / \mathrm{kg})$ produced an insignificant loss of myocardial contractility whereas the same ischaemia without propranolol produced a significant loss.

Three normothermic groups of hearts, 11 continuously perfused and given propranolol, nine ischaemic for 90 minutes without, and 10 ischaemic with propranolol showed that propranolol caused a $32 \%$ reduction in contractile force and $42 \%$ in velocity (but no reduction in compliance), which had completely recovered after 90 minutes. Without propranolol, 90 minutes of normothermic ischaemia reduced force by $62 \%$ and velocity $64 \%$, whereas with preliminary propranolol these reductions were only $42 \%$ and $27 \%$.

Low dose propranolol offers protection from preoperative ischaemia without prejudice to postoperative function.

\section{Should beta-blockers be withdrawn before coronary artery surgery-recent experience}

A SHORTHOUSE and D J PARKER One hundred consecutive patients having coronary artery surgery had beta-blocker therapy withdrawn before surgery. Ninetytwo per cent of the patients had been on beta-blockers for more than three months, $84 \%$ being on propranolol (mean dose $260 \mathrm{mg} /$ day). Seventy-five patients had triple vessel disease or left main stem disease. 
Treatment was withdrawn 24 hours before surgery in $56 \%$ and earlier in $39 \%$. In $5 \%$ it was not withdrawn. One patient with unstable angina and poor left ventricular function was treated with an intraaortic balloon while $800 \mathrm{mg} /$ day propranolol was withdrawn.

Sixteen patients developed new or exacerbated rest pain during withdrawal, and all but one of these was receiving $240 \mathrm{mg} /$ day propranolol or more. Rest pain during withdrawal was rare in patients on $120 \mathrm{mg} /$ day propranolol or less.

Seventy-four patients had three or more grafts inserted and electrocardiographic evidence of intraoperative infarction occurred in $13 \%$ of patients. There was one operative death. Intraoperative myocardial infarction was twice as common in patients who developed rebound pain on beta-blocker withdrawal. Two infarctions were recognised to be associated with the early stages of operation.

Currently patients are being operated on while receiving $120 \mathrm{mg} /$ day propranolol right up to operation uneventfully, and continuing experience is presented.

\section{Additive protective effects of hypothermia and cardioplegia during ischaemic cardiac arrest}

FRANKLIN L ROSENFELDT, DAVID J HEARSE, SALLY DARRACOTT-CANKOVIC, and MARK $V$ BRAIMBRIDGE In clinical usage cardioplegic solutions are usually combined with local cardiac hypothermia. The powerful protective effect of hypothermia makes it difficult to assess the contribution made by the cardioplegic solution. The additive protective effects of hypothermia and of an experimental cardioplegic infusate (Krebs bicarbonate $\mathrm{pH} 7.4$ with $\mathrm{K}+$ raised to $25 \mathrm{mM}, \mathrm{Mg}++$ to $16 \mathrm{mM}$ and containing $10 \mathrm{mM} \mathrm{ATP)}$ were studied in 20 dogs, which were subjected to $120 \mathrm{~min}$ of ischaemia at $20^{\circ} \mathrm{C}$. In the hypothermic group (H) 10 hearts were infused with unmodified Ringers solution at $20^{\circ} \mathrm{C}$ at the onset and after $60 \mathrm{~min}$ of ischaemia. In the cardioplegia plus hypothermia group (C) of 10 hearts identical infusion conditions were followed using the cardioplegic solution at $20^{\circ} \mathrm{C}$. Measurements of ventricular function before and after bypass showed significantly better recoveries in $\mathrm{C}$ than in $\mathrm{H}$ : recovery of cardiac output was $\mathrm{C}=92 \%, \mathrm{H}=38 \%$; LV minute work was $\mathrm{C}=62 \%, \mathrm{H}=17 \%$, and $\mathrm{LV} \mathrm{dP} / \mathrm{dt}$ was $\mathrm{C}=$ $91 \%, \mathrm{H}=43 \%$. Parallel biochemical assessments from biopsies showed that postischaemic myocardial ATP content was unchanged from control in $\mathrm{C}$ but fell significantly to $56 \%$ of control in H. Assessment of myocardial integrity by birefringence and histochemical staining showed no change in $\mathrm{C}$ but a significant deterioration in the $\mathbf{H}$.

\section{Cold cardioplegia with St Thomas's solution-two years' experience}

M V BRAIMBRIDGE, S DARRACOTT-CANKOVIC, O J LAU, and J E DUSSEK In October 1975 the routine myocardial preservation technique on one of the surgical services at St Thomas's Hospital was changed from continuous coronary perfusion at $32^{\circ} \mathrm{C}$ with a beating heart to cold cardioplegia with the St Thomas's solution (16 $\mathrm{mMol} \mathrm{MgCl}_{2}, 16 \mathrm{mMol} \mathrm{KCl}$, and $1 \mathrm{mMol}$ procaine added to 1 litre of $4^{\circ} \mathrm{C}$ Ringer's solution). Comparison with the previous two years when coronary perfusion had been used showed elimination of the complications due to coronary perfusion $(9 \%$ of aortic valve replacements including one death) and a small reduction in operative mortality in groups comparable in age, aetiology, and ventricular function. Hospital mortality of aortic valve replacement fell from $2 \%(1 / 47)$ to $0(0 / 52)$, mitral valve replacement from $15 \%(8 / 55)$ to $4 \%(2 / 55)$, and aortic and mitral valve replacement in the absence of coronary artery disease from $77 \%(10 / 13)$ to $7 \%(1 / 15)$. The mortality of saphenous vein bypass grafting rose from $0(0 / 16)$ to $2 \cdot 8 \%(1 / 36)$ over a shorter period. The incidence of postoperative low cardiac output was related to preoperative myocardial function and was the same in both series.

Biopsies of the left ventricle were taken from aortic and double valve replacements and assessed cytochemically and biophysically (change in birefringence in response to ATP and calcium). A pronounced difference was seen in preservation of the internal and external halves of the biopsies. Coronary perfusion tended to preserve the outer half of the myocardium better than the inner. Cardioplegia was considerably better at preserving the inner half.

Hypothermic ischaemic arrest in aortocoronary bypass surgery

J R PEPPER Hypothermic ischaemic arrest has been used for valve replacement for years but this method of myocardial preservation has been applied only in a limited way to operations for ischaemic heart disease. The use of local hypothermic ischaemic arrest in a group of 100 consecutive patients submitted to aortocoronary bypass surgery is described.

The method used was a modification of the Shumway technique. The efficacy of the method was shown in a pilot study of 50 patients in whom temperature probes were placed on the posterior pericardium, the anterior and posterior surfaces of the left ventricle, and within the cavity of the left ventricle. This confirmed the susceptibility of the left ventricular endocardium to inadequate cooling and identified a "warm spot" on the posterior pericardium overlying the thoracic aorta. A special plate has been designed to lie behind the heart and to allow the cooling fluid to circulate freely. In addition a comparison of mean bypass times between this method and intermittent aortic clamping with a perfused heart showed a saving of 47 minutes (mean) when hypothermic ischaemic arrest was used.

From 1976 to 1977,100 patients were operated on for coronary artery disease in a consecutive series. Of the 100 patients, 14 had single grafts, 28 double grafts, 55 triple grafts, and three quadruple grafts. Endarterectomy was performed in 20 patients, left ventricular aneurysms were resected in 10 patients, and 
concurrent valve replacement was performed in nine patients. There was one hospital death due to low cardiac output. The perioperative infarction rate was $2 \%$.

In summary 100 consecutive aortocoronary bypass grafts were performed with one death. Local hypothermic ischaemic arrest by pericardial cooling is a safe, simple, and effective method of myocardial protection for this type of operation.

\section{Cosmetic treatment of pectus excavatum using a silastic implant}

A J GUNNING The surgical treatment of pectus excavatum is, in most patients, indicated because of the embarrassment it causes. The usual surgical treatment of pectus excavatum by costal cartilage resections and the use of a metal bar to support the sternum postoperatively is a major undertaking, often leaving an unsightly scar and doubtful cosmetic end result.

A simple method of filling the defect subcutaneously with a silastic implant is described which seems to give an acceptable and satisfactory result.

Epigastric hernia after median sternotomy: a surprisingly high incidence

J E DUSSEK and H G STURZAKER Introduction: Median sternotomy for access to the pericardial cavity although described in $1897^{1}$ achieved popularity only during the past 20 years. ${ }^{2-3}$ The complications, as the incision has become almost universal in open heart surgery, are well described, ${ }^{4-8}$ but even in reports of 2394 patients in Culliford's series, ${ }^{4} 1042$ in Engelman's, ${ }^{5}$ and 748 in Hedley Brown's, ${ }^{8}$ incisional hernia has not been noted to be of significant occurrence. Sanfelipo ${ }^{7}$ in a detailed list of post-incisional complications does not mention incisional hernia. This contrasts strongly with the findings in this survey of an incidence of $12 \%$ of hernia and $10 \%$ of divarication of the recti.

Methods: For the purpose of this survey 100 consecutive patients in cardiothoracic outpatients at one London teaching hospital were examined in detail with respect to their incision. All sternotomies had been closed with Tensofil to unite the sternum. One group had been closed with nylon to the linea alba and presternal musculature, while another group had been closed with Dexon to these layers.

Results: Twelve per cent of patients had an incisional hernia and a further $10 \%$ had divarication of the recti. In addition, $22 \%$ of patients suffered from wound pain and $13 \%$ complained of Tensofil knot problems. Overall, $47 \%$ of patients had a wound complaint when seen in outpatients. Predisposing factors to hernia occurrence were sought. The type of suture material used was unrelated to the results. Respiratory complications and reoperation were, however, found to be related to postoperative hernia or divarication occurrence.

Discussion: The difference in incidence of complications as evidenced by this study, compared with previous studies, may be explained by the fact that all previous studies have been concerned with hospital complications, whereas in this series all patients were seen in outpatients up to five years after operation.

REFERENCES

${ }^{1}$ Milton, H (1897). Lancet, 1, 872-873.

${ }^{2}$ Gerbode, F, Braimbridge, M V, Melrose, D (1958). Archives of Surgery, 76, 821-824.

'Julian, O C, et al (1957). Surgery, 42, 753-761.

'Culliford, A T, et al (1976). Journal of Thoracic and Cardiovascular Surgery, 72, 714.

5Engelman, R, et al (1973). Archives of Surgery, 107, 772.

'Hehrlein, F W, Hermann, H, and Kraus, J (1972). Journal of Cardiovascular Surgery, 13, 390.

'Sanfelipo, P, and Danielson, G J (1972). Journal of Thoracic and Cardiovascular Surgery, 63, 419.

${ }^{8}$ Hedley Brown, A, et al (1969). Journal of Thoracic and Cardiovascular Surgery, 58, 2, 189-197.

\section{Comparative study of homograft valves used for} aortic valve replacement over 16 years

DONALD $N$ ROSS The first homograft valve was implanted in the subcoronary position in July 1962. During the past 16 years at the National Heart Hospital the homograft valve has been the aortic valve replacement of first choice. In order to establish the importance of the homograft valve among the other valves available to the surgeon it is necessary to present a general view of the overall results with homografts over 16 years, without reference to different methods of preservation or sterilisation. A standard method of actuarial analysis permits a fair comparison between the various types of valve used throughout the world. Using the method described by Anderson et al (1974), the probability of survival of 476 patients who received an isolated aortic valve replacement as a homograft was $59 \%$ over 13 years, including the hospital mortality. This hospital mortality was high between 1962 and 1967 during the early years of innovative surgery and has now fallen to $5 \%$ during 1972-8. In order to compare the current techniques with those in use 16 years ago it is considered fair to exclude the hospital mortalities from the comparison analyses at different periods. This also permits a comparison with the published data from other centres using other valves. Such a comparison shows that as well as an improvement in patient survival due to a lower current hospital mortality, the new techniques of homograft preparation and sterilisation have resulted in an improved probability of survival. The problem of homograft degeneration, which was $31 \%$ at 13 years for the freeze dried homograft $(2.4 \% \mathrm{pa})$, has fallen to $14 \%$ at 10 years for the frozen homograft $(1.4 \% \mathrm{pa})$ and to $2 \%$ at seven years for the fresh homografts $(0.3 \%$ pa) Despite another problem associated with homograft valves due to the technical skills required for their insertion, these valves have shown a long-term performance equal or superior to any published information on prosthetic or xenograft valves. The possibility of inserting homograft valves with the same technique as for a prosthetic valve or xenograft, thus avoiding the requirement for very high degrees of technical skill, has given a better outlook for the homograft as an aortic valve replacement. 
Congenital aortic stenosis: 10-22 years after valvulotomy

BRUCE C PATON, JAMES R STEWART, S GILBERT BLOUNT, jun, and HENRY SWAN In November 1955 Swan, using inflow occlusion and hypothermia, successfully performed the first direct vision aortic valvulotomy. Between 1956 and 196734 patients underwent aortic valvulotomy under hypothermia for congenital aortic stenosis. Average age at operation was 13 years 7 months (range 2 months to 40 years). Two patients died immediately after operation. Six patients were lost to follow-up. Mean follow-up was 15 years. Of the 26 patients followed, 16 developed some aortic insufficiency. Thirteen patients had no subsequent operation: 11 are asymptomatic, seven with mild aortic insufficiency. Three patients have stenotic gradients of 62,68 , and $70 \mathrm{mmHg}$, and will require aortic valve replacement. Two patients are symptomatic with trivial $(10,25 \mathrm{mmHg})$ aortic stenosis. Three patients had exploration without valvulotomy because of unfavourable valvular anatomy. One died suddenly eight years after operation, one had aortic valve replacement after six years, and the third had repeat valvuloplasty after nine years and is well. Ten patients have had aortic valve replacement. Three late deaths were sudden or attributed to bacterial endocarditis.

Aortic valvulotomy is a palliative operation with a $50 \%$ chance of late aortic valve replacement within $10-15$ years if operation is done in the teens. Most patients may eventually need valve replacement, but comparison of collected surgical results with natural history indicates that surgery improves longevity.

\section{Return to work in patients after operation for ischaemic heart disease}

J E DUSSEK, H THOMPSON, and B T WILliams Method: Eighty-five male patients operated on by one surgeon (BTW) in the years 1974-6 have been assessed by questionnaire and direct follow-up by the cardiothoracic unit medical social worker (HT) about their return to work at 12 months after operation.

Results: Fifty-four patients (63.5\%) were working 12 months after their operation but of this group 13 $(24.1 \%)$ had changed to a less demanding occupation. Five patients $(5.9 \%)$ had retired, and their mean age was 60.8 years.

Eighteen patients $(21.2 \%)$ were not working one year after their operation. Of these, four $(22.2 \%)$ were deemed fit to return to work but were unemployed because of local difficulties in obtaining employment and $12(66 \cdot 7 \%)$ were unable to work due to ill-health, which in two $(2 \cdot 3 \%)$ cases was directly related to their operation.

Two patients had died within twelve months of leaving hospital.

Eight patients $(9.4 \%)$ at the time of writing have been incompletely assessed, but half of this group are believed to have returned to work.

An attempt to correlate the length of time off sick before operation with return to work is complicated by the great variations within the areas of referral.
In one rural area in one year the mean time off sick was 27 months whereas in London it was 4.8 months. The length of time taken to return to work again varied from area to area.

One referring source had an active rehabilitation programme and the mean time for return to work there is to be compared with the results in the other areas.

\section{Pathology of the intima in coarctation of the aorta:} a study using light and scanning electron microscopy

A KENNEDY, D G TAYLOR, and T E DURRANT In the $\omega$ adult type of coarctation of the aorta the lumen is constricted by a shelf of fibromuscular tissue that protrudes from the dorsal wall of the aorta at a point $\mathrm{N}$ near the site of insertion of the ligamentum arteriosum. The intima covering this constricting shelf has been studied using conventional light microscopy and scanning electron microscopy of surgical specimens of coarctation removed at ages varying from 2 to 46 years. Immediately proximal to the stenosis, the intima was found to run in fine longitudinal folds that radiated into the orifice. On the distal side of the shelf the intima was grossly irregular with deep longi- $\downarrow$ tudinal folds and transverse folds that gave it a convoluted appearance resembling the surface of the brain. In adults and older children the intima immediately distal to the orifice was covered with a featureless layer which by light microscopy is seen to be laminated, to be distinct from the elastica, and which of ten gave positive staining reactions for fibrin. Intimal thickness increased irregularly with age but large increases of $500 \mu$ or greater were found only in patients over the age of 15 years. These findings are consistent with the view that the constriction has both a fibroelastic component that is congenital and a fibrous component that is acquired and progressive. It is suggested that this progressive element is due to $?$ the deposition of fibrin on an abnormal intimal surface in a region of turbulent blood flow. Such a mechanism would explain the occasional recurrence of coarctation 8 of the aorta after surgery. This may be due to failure to remove the abnormal area of endothelium completely and to persistent abnormalities of blood flow at the site of anastomosis.

\section{Improved results with the Blalock-Taussig shunt in} infants

J WALLWORK and P K CAVES General dissatisfaction with the long-term results of the Waterston shunt $\sigma$ performed in infancy has led to reconsideration of the Blalock-Taussig shunt in this age group, as well $\stackrel{\circ}{工}$ as the introduction of polytetrafluoroethylene vascular $\mathbb{E}$ grafts. The chief difficulties with the subclavian artery : as a shunt in infants have been its short length if $T^{\circ}$ divided proximal to its branches, or its narrow diameter if divided distally. We have attempted to $\stackrel{\Phi}{\Phi}$ overcome these difficulties with the Blalock-Taussig $\mathbb{\mathbb { D }}$ shunt in infants by using a modified technique that $\frac{\sigma}{\sigma}$ includes: 
(1) systemic heparinisation $(2 \mathrm{mg} / \mathrm{kg})$ without protamine reversal;

(2) preferential use of the subclavian artery rising from the innominate artery;

(3) distal ligation of the branches of the subclavian artery and of the subclavian artery itself, which are divided without proximal ligation;

(4) the open ends of the branches and the distal subclavian artery are cut to make one common expanded terminal opening on the subclavian artery;

(5) construction of a 5-6 mm long anastomosis to the main pulmonary artery using continuous and interrupted 7/0 Prolene sutures;

(6) frequent arterial blood gas monitoring; and

(7) avoidance of hypotension.

In the past 12 months we have performed 12 Blalock-Taussig shunts for tetralogy of Fallot (five patients, aged 2 days -7 months), primitive ventricle + pulmonary atresia (five patients, aged 1-8 months), pulmonary atresia +VSD (aged 4 months), and pulmonary valve atresia (aged 4 days).

All shunts have functioned well as evidenced by the presence of a loud shunt murmur and rise in the arterial $\mathrm{PO}_{2}$. There have been no early or late shunt closures (follow-up 1-12 months). All the infants are thriving.

Our experience suggests that the Blalock-Taussig shunt, properly constructed, may be the shunt of choice for cyanotic congenital heart disease in infancy.

\section{Tracheobronchial reconstruction. Experience with a prosthesis of Marlex mesh and pericardium}

$\mathrm{K}$ MOGHISsI During the period January 1971January 1978 we have carried out 97 tracheobronchial resections in neoplastic cases. Our policy has been to consider reconstruction by various plastic procedures without the use of graft if possible. In 21 patients reconstruction was carried out by employing prostheses (the prosthesis and the technique of its insertion has been previously described-and would be illustrated).

These 21 patients may be divided into three groups:

Group 1: In five patients there was a tracheal neoplasm without pulmonary or bronchial involvement; in these resection of various lengths of the trachea was followed by reconstruction using circumferential tubular grafts in two patients and partial circumferential replacement in three.

Group 2: In eight patients the tumour was a right bronchial one extending to the trachea. In these a right pneumonectomy and excision of variable lengths of the lateral wall of the trachea $\left(\frac{1}{3}-\frac{3}{4}\right.$ circumference) was carried out, followed by reconstruction using the graft. In four of these cases the carina was resected together with the lung.

Group 3: In eight patients a right upper lobectomy was carried out together with the lower lateral wall of trachea. In three of these a sleeve of the right main bronchus was excised.

A patch graft was used in all these patients.
RESULTS

No graft has failed to take-the follow-up has been up to seven years.

Group 1: One patient died six weeks after operation by erosion of the innominate artery (this patient had total circumferential replacement). Two patients died seven and 18 months after operation. Two patients are still alive five and $a$ half and seven and a half years after operation.

Group 2: One patient died four days after operation (pulmonary embolus). Three patients died at six, 15, and 18 months respectively. Two patients are alive four and a half and one and a half years after operation.

Group 3: Four patients are alive at five and a half, five, two and a half and two years respectively. Four patients died 18-24 months after operation.

CONCLUSIONS

(1) Marlex Mesh/pericardium is a sound prosthesis for patch or partial circumferential reconstruction of trachea and main bronchi.

(2) In circumferential airway reconstruction its use has been successful in one case only. In the circumferential defects as far as possible the graft should not be employed. However, if the use of the prosthesis becomes inevitable the circumferential defect should be converted to a partial circumferential one first, then a patch graft can be applied.

(3) Use of graft permits excision of the lower trachea and carina with easy reconstruction.

\section{Twelve years' experience of oesophageal atresia and fistula}

$M$ VANCINI and L D ABRAMS All cases were treated by immediate operation. The fistula was divided and sutured. Primary anastomosis was done whenever technically possible, even under tension. Other patients were "staged."

Postoperative mortality : Nine cases (12\%).

The cases have been divided into three groups by weight:

Less than $2 \mathrm{~kg}$

Six cases $(8 \%)$

Three primary; one death $(33 \%)$

Three staged (50\%); three deaths $(100 \%)$

$2 \mathrm{~kg}-2 \cdot 5 \mathrm{~kg}$

16 cases $(21 \%)$

10 primary; one death $(10 \%)$

Six staged; no deaths

More than $2.5 \mathrm{~kg}$

53 cases $(71 \%)$

46 primary; four deaths $(9 \%)$

Seven staged $(13 \%)$; three deaths $(43 \%)$

The risk is no higher for babies between 2 and $2.5 \mathrm{~kg}(6 \%)$ than those over $2.5 \mathrm{~kg}(13 \%)$. The risk is very high only for those less than $2 \mathrm{~kg}(66 \%)$.

Three babies died late-one with primary anastomosis, and two awaiting colon graft. The remaining 11 "staged" cases are all alive with colon grafts.

The incidence of suture line stricture in this series is low-about $6 \%$. 
Spontaneous rupture of the oesophagus and the mechanics of retching and vomiting

ROBERT MARSHALL Experimental rupture of the isolated post-mortem oesophagus may be achieved by applying pressures which are within the range of those capable of being produced during life, if the pressures are applied suddenly and repeatedly. Intragastric and intraoesophageal pressures have been recorded in two normal subjects during retching and in one patient during vomiting. The muscular action during retching and vomiting is discussed in relation to the occurrence of spontaneous rupture of the oesophagus. The mi:sles producing the force required for vomiting differ from those that supply the force for rupturing the oesophagus.

Haemodynamic benefits of pulsatile perfusion-effects on peripheral vascular resistance and the reninangiotensin system

$K$ M TAYLOR, $S$ MITTRA, W $H$ BAIN, $P$ K CAVES, $J$ J BRANNAN, and J J MORTON The occurrence of increasing peripheral vasoconstriction in association with conventional non-pulsatile cardiopulmonary bypass (CPB) is a well-recognised but poorly understood phenomenon. We have previously indicated the possible involvement of the renin-angiotensin system in this syndrome by showing a pronounced rise in the plasma level of the vasoconstrictor angiotensin II (AII) during and for the first few hours after nonpulsatile CPB (Taylor et al, 1977).

The Stöckert pulsatile pump system has been employed in a comparative study designed to investigate the relative effects of pulsatile and non-pulsatile perfusion on peripheral vasoconstriction and on the plasma level of angiotensin II during the period of CPB.

Twenty-four unselected patients submitted to elective open-heart procedures were studied. Twelve had conventional non-pulsatile CPB (non-pulsatile group) and 12 had pulsatile CPB during the period of total CPB (pulsatile group). There were no significant differences between the groups in respect of age, weight, total bypass time, or cross-clamp time.

Calculation of the peripheral vascular resistance index (PVRI) and measurements of plasma AII levels $(\mathrm{pg} / \mathrm{ml})$ were obtained at the start (CPB1) and the end (CBP2) of the period of CPB. The results (mean values \pm SEM) were as follows:

\begin{tabular}{|c|c|c|c|}
\hline & Non-pulsatile & Pulsatile & P-value \\
\hline PVRI (CPB1) & $19 \cdot 60 \pm 0.9$ & $20 \cdot 89 \pm 0.8$ & NS \\
\hline PVRI (CPB 2) & $29 \cdot 96 \pm 1.4$ & $21 \cdot 45 \pm 0.9$ & $<0.005$ \\
\hline$\triangle$ PVR & $10 \cdot 36 \pm 0 \cdot 8$ & $0.56 \pm 0.7$ & $<0.001$ \\
\hline Plasma & & & \\
\hline AII (CPB1) & $49 \pm 15$ & $44 \pm 13$ & NS \\
\hline Plasma & & & \\
\hline AII (CPB2) & $226 \pm 40$ & $98 \pm 16$ & $<0.01$ \\
\hline$\triangle$ Plasma AII & $117 \pm 33$ & $54 \pm 14$ & $<0.01$ \\
\hline
\end{tabular}

These results indicate that pulsatile CPB significantly reduces the rise in peripheral vascular resistance associated with non-pulsatile flow. This effect may be achieved by preventing excessive rises in the plasma level of the vasoconstrictor angiotensin II during the period of pulsatile perfusion.

REFERENCE.

Taylor, K M, Morton, J J, Brown, J J, Bain, W H, and Caves, P K (1977). Journal of Thoracic and Cardiovascular Surgery, 74, 6, 840.

\section{Study of the factors contributing to the mortality} associated with open-heart surgery in infants

D K C COOPER About $40 \%$ of children with congenital heart disease die within the first year of life if untreated surgically. The results of surgical correction in 212 patients under the age of 1 year undergoing open-heart surgery at the Hospital for Sick Children between 1973 and 1977 inclusive have been analysed.

There were 53 hospital deaths giving an overall mortality of $25 \%$. Twenty per cent of patients were neonates, and in this group the mortality was $58 \%$. Operations for simple TGA and VSD carried a low mortality $(3 \%)$, whereas several more complex conditions carried a mortality above $40 \%$.

The presence of "uncorrectable" anatomical deformities (15) or of irreversible pulmonary vascular disease (3) were factors in 18 deaths $(34 \%)$. Occasionally these findings were associated with errors in preoperative diagnosis but more commonly the diagnosis was correct but the anatomy grossly unfavourable in some respect. Eight patients $(15 \%)$ presented for operation in a moribund state despite intensive medical support. Mistakes in management were factors in 15 deaths $(28 \%)$; these included complications of investigation, errors of surgical judgment, mistakes in surgical technique, or errors in postoperative care. Infection accounted for only two deaths $(4 \%)$, and in 10 deaths $(19 \%)$ the cause remained unclear.

The author is indebted to the surgeons of the thoracic unit at the Hospital for Sick Children (Mr J Stark and Mr M De Leval) for their encouragement and guidance in the completion of this study.

\section{Long-term effect of intra-aortic balloon} counterpulsation on left ventricular performance

T A ANGERPOINTER, $P$ G JACKSON, and B $T$ WILLIAMS The intra-aortic balloon pump (IABP) has become an $D$ established technique in the management of severe postoperative left ventricular (LV) failure. In patients who are cardiopulmonary bypass dependent, IABP $ᄋ$ may be life saving. This paper reports the treatment $N$ of such a patient whose postoperative course was $N$ monitored using an indwelling electromagnetic aortic $\omega$ flow probe. The measurement of aortic flow enables a beat-by-beat assessment of cardiac output (CO) and 0 stroke volume (SV) to be made, but, more im- $\mathbb{D}$ portantly, when phasic aortic flow is combined with $\stackrel{\infty}{+}$ the measurement of phasic arterial pressure it is pos- $\square$ sible to derive LV stroke work (SW) and ventricular 0 afterload (VA) also on a beat-to-beat basis. These $\mathbb{\varnothing}$ two variables are fundamental aspects of LV perform- $\overrightarrow{\mathbb{D}}$ ance, and they are not amenable to long-term $\cong$ measurement by any other means. In this case these 
and other variables were observed over an eight-day period of postoperative balloon assistance.

At the start of the study $\mathrm{CO}$ nearly doubles from 2.20 to $4.08 \mathrm{l} / \mathrm{min}$. After 15 hours of assistance the CO was $3.441 / \mathrm{min}$ off IABP, rising to $4.021 / \mathrm{min}$ on assistance-a $50 \%$ improvement. This degree of improvement persisted until the fifth postoperative day when the patient was extubated. Thereafter IABP continued to increase $\mathrm{CO}$, but to a lesser degree. At 144 hours of IABP, for example, there is a $25 \%$ improvement from 3.85 to $4.86 \mathrm{l} / \mathrm{min}$. This order of improvement persisted until the patient was weaned from IABP. The trial measurement of $\mathrm{CO}$ which was made 190 hours after CPBP was $4.40 \mathrm{l} / \mathrm{min}$.

LAP was invariably reduced with IABP. At the start of the study LAP fell by $35 \%$ from $23 \mathrm{mmHg}$ to $15 \mathrm{mmHg}$; however, the extent of the reduction decreased steadily until IABP was withdrawn. The arterial pressure is given as the peak arterial pressure (marked systolic) and the end diastolic pressure (marked diastolic) in fig 1 . It can be seen that during the period of recovery the unassisted peak systolic pressure approaches the peak diastolic pressure achieved on IABP.

The impact of IABP on aortic peak flow (AoPF) is considerably less in the later tracing. At 24 hours IABP increased AoPF from 11.36 to $14.621 / \mathrm{min}$ $(28.7 \%)$ whereas the values at 168 hours were 20.40 and 23.41 representing a $14.8 \%$ increase.

There was an inconsistent relationship in SW on and off IABP. During the first 24 hours IABP increased LV SW by up to $50 \%$. Thereafter the relationship was inconsistent.

IABP produced a major reduction in afterload. VA can be seen to approach the unassisted values during the two weaning periods.

\section{Long-term follow-up after reconstructive atrioventricular valve surgery. Clinical and haemodynamic results of flexible ring annuloplasty}

CARLOS G DURAN, JOSE L POMAR, JOSE C CORDO, ALBERTO OCHOTECO, and JOSE L UBAGO In 1975 we reported to this Society our initial clinical experience with a totally flexible ring for atrioventricular valve reconstruction. Over three years, 310 such rings have been used at our institution representing $29 \%$ of all our mitral and $94 \%$ of our tricuspid surgery. Up until January 1978, 158 have been placed in the mitral and 152 in the tricuspid position. In the group of 109 patients with isolated mitral ring annuloplasty there was no operative mortality. Actuarial curves showed a $98.2 \%$ survival at 36 months. Mitral and tricuspid ring annuloplasty was simultaneously performed in 49 patients; there were two early and one late deaths. In the group of 103 patients with tricuspid rings the actuarial curves showed $94 \%$ survival at three years.

Seven patients had to undergo reoperation-four cases for ring dehiscence and three for failure of the plastic procedure. No deaths occurred in this group. Up to date, $94.6 \%$ of the surviving patients are free of thromboembolic complications.
Fifty-eight patients with a mitral ring have been recatheterised showing a mean basal transmitral gradient of $9.9( \pm 4.1)$ and $13.7( \pm 5.9)$ after volume load. Mean postoperative mitral area was of 2.42 $( \pm 0.86) \mathrm{sq} \mathrm{cm}$.

In conclusion, it is felt that flexible ring annuloplasty associated to an accurate repair of the whole valvular complex is a safe, stable, and therefore valuable technique, which reduces the high incidence of valve replacements.

\section{Results of surgery for oat cell carcinoma of the bronchus}

D F SHORE and M PANETH Surgery is of ten withheld from patients in whom the diagnosis of oat cell carcinoma of the bronchus is made since surgical results are generally considered to be no better than other modes of treatment. It is our policy to exclude only those patients who have lesions judged inoperable on bronchoscopy, evidence of distant metastases, or else who are considered to be medically unfit to withstand lung resection. Otherwise we have used the same criteria for selection as with other histological types of carcinoma of the bronchus.

Using this policy 40 patients had resections for oat cell carcinoma between 1960 and 1975. During the same period 24 patients underwent thoracotomy but were found to have inoperable lesions. Twenty patients underwent radical pneumonectomy, 18 patients lobectomy, and two patients bilobectomy. In each case the lymphatic fields were extirpated as completely as was possible.

Eleven patients remain alive and well with no evidence of recurrence. Ten of these patients have survived five years or more, giving an overall five year survival of $25 \%$.

We conclude that surgery should be considered as a possible first line of treatment in patients with oat cell carcinoma of the bronchus.

\section{Palliative intubation of the trachea and main bronchi}

D B CLARKE Six patients presenting with stridor due to malignant obstruction of the trachea or the origins of the main bronchi were treated by emergency insertion of $6 \mathrm{~mm}$ Souttar's tubes through the obstructed segment. This succeeded in producing immediate relief of symptoms in five, with survival of up to 16 months. One patient required intubation of both main bronchi and the oesophagus. The method is commended for its simplicity, its effective palliation, and for safety of subsequent radiotherapy.

\section{Alveolar soft part sarcoma}

R L HURT Alveolar sof t part sarcoma is a slow growing but highly malignant soft-tissue tumour only recognised as a clinical entity during the past 10 years.

It affects most of ten the deep soft tissues of the leg of young adults, especially women, and commonly produces pulmonary blood-borne metastases. These metastases are its usual mode of presentation, and the primary growth may not always be apparent. 
It has two unique characteristics, unknown in any other tumour-an unusual age/sex distribution and a special tendency to occur on one side of the body.

Six cases of this rare tumour are described, the literature briefly reviewed, and the treatment discussed.

\section{Studies of the experimental basis for coronary surgery}

D J Wheatley Despite vast clinical experience of coronary surgery accumulated over the past decade, uncertainty about its role persists. Relatively little experimental justification for aortocoronary bypass grafting is available.

Although preventative measures, development of collateral vessels, and medical measures to modify myocardial perfusion requirements have an important place in the course of coronary disease, surgery offers an attractive theoretical prospect of improvement. In order to study the theoretical aspects of coronary surgery we have developed an animal model that allows production of angiographically documented acute coronary stenosis. Using tracer microspheres the influence of stenosis on myocardial perfusion has been studied and correlated with haemodynamic changes in the affected vessel. The effectiveness of a bypass graft can also be shown.

Since Rudolph and Heymann popularised the technique in 1967, tracer microspheres have been applied to myocardial bloodflow measurement by many workers. We have improved the accuracy of the method of injecting microspheres into the arterial line of an extracorporeal circuit with temporary occlusion of much of the aortic run-off, thus ensuring up to $25 \%$ of injected microspheres being diverted to myocardium. This allows good-resolution mapping, making fairly accurate localisation and quantitation of perfusion deficits possible.

We have shown that perfusion deficits are present with relatively minor degrees of stenosis when coronary flow is high, possibly justifying surgery for stenosis of less than $50 \%$ of lumen. A potential cause of long-term graft occlusion is also suggested by very low graft flow where a stenosis is sufficiently mild to produce little pressure drop over it. It is hoped that application of the principles illustrated will improve our coronary surgical results in clinical practice.

\section{Evaluation of aortocoronary bypass surgery by} thallium 201 myocardial perfusion imaging

PATRICK S ROBINSON, A CROWTHER, D J COLTART, M M WEBB-PEPLOE, and B T WILLIAMS Twenty-one patients presenting with angina pectoris underwent evaluation by exercise testing and myocardial perfusion imaging using thallium 201 (T1201) before and after aortocoronary bypass surgery.

About six months after surgery 17 patients were symptom free, two were symptomatically improved, and two unchanged. On a standard exercise protocol, exercise duration averaged $8.56( \pm 3.44)$ minutes preoperatively and $10.65( \pm 2 \cdot 37)$ minutes postoperatively $(P<0.01)$. The exercise ECG showed evidence of ischaemia in 16 patients preoperatively; after operation three patients had definite (but less pronounced) electrocardiographic evidence of $\vec{\theta}$ ischaemia and one had new $Q$ waves suggesting perioperative myocardial infarction.

Before operation 17 of the 21 patients had defects on exercise T1201 imaging consistent with ischaemia. After operation T1201 imaging suggested complete revascularisation in 15 patients with partial revascularisation in three and evidence of perioperative myocardial infarction in three. The limitations of symptomatic and electrocardiographic assessment are discussed.

T1201 myocardial imaging is a useful technique to assess aortocoronary bypass surgery both to provide evidence of relief of myocardial ischaemia and to show myocardial damage occurring in the perioperative period. 